\title{
Obesity-Associated MiR-342-3p Promotes Adipogenesis of Mesenchymal Stem Cells by Suppressing CtBP2 and Releasing C/EBP $\alpha$ from CtBP2 Binding
}

\author{
Liang Wang Lei Xu Min Xu Guoqiang Liu Jian Xing Caifeng Sun Huifang Ding
}

Shengli Oilfield Central Hospital, Dongying, Shandong, P.R. China

\section{Key Words}

Mesenchymal stem cells • miR-342-3p • Obesity • Adipogenic differentiation • CtBP2

\begin{abstract}
Background/Aims: The elucidation of the molecular mechanism of adipocyte differentiation in mesenchymal stem cells is of essential importance for the development of treatments for metabolic diseases, such as obesity and diabetes. Methods: The expression levels of miR$342-3 p$ and carboxy-terminal binding protein 2 (CtBP2) were regulated by oligonucleotide transfection. Adipogenic differentiation was induced by adipogenic medium containing indomethacin, dexamethasone and 3-isobutyl-1-methylxanthine on day 12 , as determined by Oil Red $O$ staining and triglyceride concentration assay to assess intracellular lipid accumulation. The induction of adipocyte-specific transcription factors and markers was detected by qRT-PCR and western blot. The regulation of CtBP2 expression by miR-342-3p was determined by western blot, qRT-PCR, luciferase reporter assay, ChIP assay and functional experiments. Results: We revealed that miR-342-3p was enriched in the adipose tissue of obese mice, and its expression was significantly elevated during adipogenic differentiation in both human mesenchymal stem cells (hMSCs) and 3T3L1 cells. Using gain- and loss-offunction assays, we demonstrated that the overexpression of miR-342-3p markedly promoted the differentiation of hMSCs into an adipogenic lineage. Adipogenesis was significantly blocked by miR-342-3p downregulation. We identified and validated that CtBP2 was a direct target of miR-342-3p in this process. The effects of the inhibition of CtBP2 were similar to those of miR-342-5p overexpression on adipogenic differentiation, promoting the release of C/EBP $\alpha$ from CtBP2 binding. Conclusion: miR-342-3p is a powerful enhancer of the adipogenesis of human adipose-derived MSCs that acts by inhibiting CtBP2 and releasing the key adipogenic regulator $\mathrm{C} / \mathrm{EBP} \alpha$ from $\mathrm{CtBP2}$ binding, subsequently activating the expression of adipogenic transcription factors and markers.
\end{abstract}




\section{Cellular Physiology Cell Physiol Biochem 2015;35:2285-2298 \begin{tabular}{l|l} 
and Biochemistry Published online: April 13, 2015 & $\begin{array}{l}\text { C) 2015 S. Karger AG, Basel } \\
\text { www.karger.com/cpb }\end{array}$ \\
\hline
\end{tabular} \\ Wang et al.: MiR-342-3p Regulates Adipogenesis via Suppressing CtBP2}

\section{Introduction}

Obesity is a major health concern worldwide and is associated with increased risks of chronic diseases, such as metabolic syndrome (hyperlipidemia, insulin resistance, type 2 diabetes, etc.), atherosclerosis, chronic inflammation, cardiovascular disease and cancer [1-3]. Adipocytes are derived from mesenchymal stem cells or progenitor cells, which undergo a lineage-specific differentiation process termed adipogenesis or adipogenic differentiation that occurs in two phases, namely commitment to the preadipocyte lineage and terminal differentiation; ultimately, these cells undergo differentiation into mature adipocytes [4]. The stromal cell population derived from adipose tissue has been termed adipose-derived mesenchymal stromal cells or adipose tissue-derived mesenchymal stem cells (AMSCs). These cells have extensive proliferative potentials and are able to differentiate into adipogenic, osteogenic, chondrogenic and myogenic lineages [5-8]. The elucidation of the molecular mechanisms involved in the adipocyte differentiation of AMSCs is of essential importance for the development of therapeutics for metabolic diseases, such as obesity and diabetes.

MicroRNAs (miRNAs) are $\sim 22$ nucleotide-long, small, non-coding, single-stranded RNAs that mediate gene suppression by binding to the 3' untranslated regions (3'UTRs) of target mRNAs and either promoting degradation or inhibiting translation [9]. They have been shown to play regulatory roles in several biological processes, including cell proliferation, differentiation, apoptosis and tumor oncogenesis [10-13]. Recently, increasing evidence has demonstrated that miRNAs play critical roles in osteoblast differentiation. For example, miR-196a, miR-335-5p, miR-322, miR-26a, miR-26b, miR-29b, miR-1192, miR-218, miR-378, miR-548d-5p and miR-302a accelerate osteogenic differentiation [14-22], while miR-26a, miR-133, miR-135b, miR-138, the miR-30 family, miR-155, miR-100, miR-433, miR-145, miR-143, miR-542-3p, miR-338-3p, miR-140-5p and miR-146a impair osteoblast differentiation [23-35]. Many miRNAs have been reported to be involved in the regulation of adipogenic differentiation, such as miR-143, miR-17-92, miR-130, miR-138, miR-17-5p, miR-106a, miR-210, miR-709, miR-137, and miR-302 [36-44]. However, few miRNAs have been reported in association with obesity and the positive regulation of adipogenesis [45]. Therefore, future studies are warranted to understand the exact role of obesity-associated miRNAs in the adipogenic differentiation of AMSCs.

In this study, we characterized miR-342-3p, which is upregulated during the development of obesity [46], and investigated its effects on the adipogenic differentiation of human adipose-derived MSCs (hAMSCs). Our results indicate that miR-342-3p is an important positive regulator of adipogenesis. Using target prediction and luciferase reporter assays, we demonstrated that carboxy-terminal binding protein 2 (CtBP2), a corepressor of $\mathrm{C} / \mathrm{EBP} \alpha$ [47], is a direct target of miR-342-3p. Our findings provide further insights into the mechanisms of the regulation of adipocyte differentiation by miRNAs.

\section{Materials and Methods}

\section{Cell culture}

This study was approved by the Ethical Committee of the Shengli Oilfield Central Hospital. hAMSCs were isolated from five donors who provided informed consent. These cells were harvested and cultured according to previously described methods $[8,48]$ and were maintained in Dulbecco's modified Eagle's medium supplemented with $10 \%$ fetal bovine serum, $100 \mu \mathrm{g} / \mathrm{ml}$ streptomycin and $100 \mathrm{mg} / \mathrm{ml}$ penicillin in a $5 \% \mathrm{CO}_{2}$ environment at $37^{\circ} \mathrm{C}$ according to standard protocols. All hAMSC experiments were performed at passage 3 to 4 .

Induction and identification of adipocyte differentiation

Adipocyte differentiation was induced by culturing hAMSCs for 12 days in an adipocyte induction medium (10\% FBS, $200 \mu \mathrm{M}$ indomethacin, $1 \mu \mathrm{M}$ dexamethasone, and $0.5 \mathrm{M}$ 3-isobutyl-1-methylxanthine in 


\section{Cellular Physiology Cell Physiol Biochem 2015;35:2285-2298 \begin{tabular}{ll|l} 
and Biochemistry 10.1159/000374032 & $\begin{array}{l}\text { Published online: April 13, } 2015 \\
\text { w } 2015 \text { S. Karger AG, Basel } \\
\text { www.karger.com/cpb }\end{array}$ \\
\hline
\end{tabular} \\ Wang et al.: MiR-342-3p Regulates Adipogenesis via Suppressing CtBP2}

$\alpha$-MEM). The extent of differentiation was assayed by measuring adipogenesis-related genes and was also evaluated by Oil Red 0 staining and measuring the triglyceride concentration as indicators of intracellular lipid accumulation.

\section{Oil Red 0 staining}

Cells were washed with phosphate-buffered saline (PBS) and fixed with 4\% paraformaldehyde for 10 min at room temperature. They were then washed twice with deionized water, stained with saturated Oil Red 0 solution (stock solution: $3 \mathrm{mg} / \mathrm{ml}$ in isopropanol; working solution: $60 \%$ Oil Red 0 stock solution and $40 \%$ distilled water) for $30 \mathrm{~min}$ at room temperature. After staining, the cells were fully washed with distilled water to remove unbound dye, visualized by light microscopy, and photographed. To obtain quantitative data, intracellular absorbed Oil Red 0 was extracted into a 96-well plate with $100 \%$ isopropanol, and absorbance was measured at $510 \mathrm{~nm}$.

Triglyceride concentration measurement

Cells were washed with PBS after the culture medium was removed. The triglyceride concentration in the washed cells was then measured using a glycerol assay kit (Applygen, Beijing, China).

Quantitative real-time polymerase chain reaction ( $q$ RT-PCR)

Total RNA was isolated from cultured cells using TRIzol reagent (Invitrogen, Beijing, China) for mRNA and a miRVana miRNA Isolation Kit (Life Technologies, Beijing, China) for miRNA, respectively, according to the manufacturer's instructions. For mRNA amplification, reverse transcription was performed using $1 \mu \mathrm{g}$ of total RNA with M-mlv reverse transcriptase (TaKaRa).

For miRNA amplification, reverse transcription was performed using $1 \mu \mathrm{g}$ total RNA with a Ncode miRNA First-strand cDNA Synthesis Kit (Invitrogen, USA), according to the manufacturer's instructions. Beta-actin was used as a normalizing control for the mRNA, and U6 was used as a normalizing control for the miRNA. PCR was performed using Power SYBR Green PCR Master Mix with an ABI 7500 Instrument (Applied Biosystems, Foster City, CA). To perform qRT-PCR, cDNA prepared from mRNA was mixed with Power SYBR Green PCR Master Mix (Applied Biosystems, Foster City, CA), and miRNA-specific cDNA was mixed with TaqMan Universal Master Mix (Life Technologies, USA). All samples were analyzed with an Applied Biosystems 7500 Fast Real-Time PCR system. Each reaction was performed at least in triplicate and repeated with at least three different samples. Quantifications of the fold changes in gene and miRNA expression were performed using the $2^{-\Delta \Delta \mathrm{Ct}}$ method.

\section{Western blot analysis}

Samples were harvested and lysed in ice-cold radio immunoprecipitation assay (RIPA) lysis buffer plus protease inhibitors (Beyotime, Nanjing, China). Equal protein amounts were loaded and separated by $10 \%$ SDS-PAGE. They were then transferred to a PVDF membrane (Millipore, USA), blocked by incubation with $5 \%$ fat-free milk, and probed with the primary antibodies anti-CtBP2, anti-PPAR $\gamma$, anti-C/EBP $\alpha$, anti-FABP4 and anti-LPL at $4{ }^{\circ} \mathrm{C}$ overnight. After washing, the blots were incubated with horseradish peroxide-conjugated secondary antibodies at room temperature for $1 \mathrm{~h}$. The blots were developed with chemiluminescent ECL reagent (Millipore, USA). GAPDH was used as a loading control.

\section{Cell transfection assay}

Transfections were performed using Lipofectamine 2000 (Invitrogen, USA) according to the manufacturer's instructions. Cells were seeded with complete medium without antibiotics. On the following day, $100 \mathrm{nM}$ of miRNAs (miR-342-3p mimics or inhibitors, GenePharma, Shanghai, China) and $100 \mathrm{nM}$ of siRNAs (GenePharma, Shanghai, China) for CtBP2 were transfected into cells with a miRNA/inhibitor negative control (NC/NCI) or non-targeting siRNA as a negative control (siNC). Six hours after transfection, the medium was replaced with a maintenance medium or induction medium, according to the requirements of further experiments.

Vectors, DNA constructs and dual luciferase reporter assay

A putative miR-342-3p-recognition element in CtBP2 was cloned into the 3 ' untranslated region (UTR) of a firefly luciferase reporter vector according to the manufacturer's instructions. Oligonucleotide 
sequences were designed and ligated into a luciferase reporter vector (p-MIR-Report; Ambion). The following oligonucleotides were used in these experiments: pMIR-CtBP2 (pMIR-CtBP2-wt) FW, 5'GAGCT CAGAAGTATGTTTTGTTTTA GTGTGAG TTACCGTTACTGTATTTGTT A-3' and RV, 5'- CGCGT AACAAATACAGTAACGGTAA CTCACAC TAAAACAAAACATACTTCTG C-3'; and pMIR-CtBP2-WT-mut (pMIRCtBP2-M) FW, 5'- GAGCT CAGAAGTATGTTTTGTTTTA GAATCCG TTACCGTTACTGTATTTGTT A-3' and RV, 5'CGCGT AACAAATACAGTAACGGTAA CTTAGGC TAAAATAAAACATACTTCTG C-3'. The sequences of the miR342-3p binding site and mutant site are shown in bold. Each vector, along with 100 ng pMIR- $\beta$-gal plasmids and $100 \mathrm{nM}$ miR-342-5p mimics or NC, was cotransfected into 293T cells using Lipofectamine 2000 reagent (Invitrogen, USA). At $24 \mathrm{~h}$ after transfection, cells were harvested. Renilla and firefly luciferase activities were measured using a Dual-Luciferase Reporter Assay System (Luciferase Assay System, Promega, USA). Transfections were performed in triplicate, and all experiments were repeated three times. Luciferase activity was normalized to $\beta$-galactosidase activity.

\section{ChIP assay}

A total of $2 \times 10^{6}$ cells were fixed with $1 \%$ formaldehyde at room temperature for $10 \mathrm{~min}$. Crosslinking was stopped with $0.125 \mathrm{M}$ glycine, and the cultures were incubated for $2 \mathrm{~min}$. The cells were then scraped, and nuclear extracts were prepared and sonicated with an EZ-Magna ChIP G Chromatin Immunoprecipitation (ChIP) Kit (Millipore, USA) according to the manufacturer's instructions. The lysates were pelleted and precleared, and each lysate was incubated with $1 \mathrm{mg}$ of one of the following antibodies and rotated at $4^{\circ} \mathrm{C}$ overnight with magnetic protein G beads (Roche, Switzerland): anti-CtBP2 (Santa Cruz, China) or immunoglobulin G (IgG). The complexes were eluted with buffer containing 1\% SDS and $0.1 \mathrm{M}$ $\mathrm{NaHCO3}$, and crosslinks were reversed at $65^{\circ} \mathrm{C}$. DNA was recovered by phenol-chloroform extraction and ethanol precipitation and then subjected to PCR analysis.

\section{Statistical analysis}

All results are presented as the mean \pm SEM. Comparisons between groups were analyzed using student $t$-tests (two-sided) with SPSS 17.0. Statistical significance was defined as a P value $<0.05$.

\section{Results}

Obesity-associated miR-342-3p is upregulated during adipogenesis

MiR-342-3p had been demonstrated to be upregulated during the development of obesity in C57BLJ6 mice fed a high-fat diet [46]. We found that the expression of miR-3423 p was higher in obese C57BLJ6 mice compared with normal mice (Fig. 1A). TargetScan confirmed that this miR is conserved between humans and mice (Fig. 1B). To investigate the role of miR-342-3p in the adipogenesis of hAMSCs, its expression pattern was analyzed in these cells in response to adipogenic induction medium by qRT-PCR. The results showed that adipogenic induction led to an 8.78-fold upregulation in miR-342-3p expression in the hAMSCs (Fig. 1C). To further verify that miR-342-3p is induced during adipocyte differentiation, we detected its expression in 3T3L1 cells cultured in adipogenic induction medium and found that it was also significantly increased in these cells (Fig. 1D). Therefore, we postulated that miR-342-3p may play an important role in adipocyte differentiation.

\section{MiR-342-3p overexpression promotes adipogenesis of hAMSCS}

To study the effects of miR-342-3p on the adipogenic differentiation of hAMSCs, synthetic miR-342-3p mimics (342-3p) along with their respective negative control (NC) were transiently transfected into hAMSCs. qRT-PCR analysis confirmed that the expression of miR-342-3p was increased by 17.58-fold in the hAMSCs transfected with miR-342-3p mimics (Fig. 2A). Next, hAMSCs were transfected with $100 \mathrm{nM}$ of miR-342-3p mimics or $100 \mathrm{nM}$ of NC and induced with adipogenic induction medium containing 10\% FBS, 200 $\mu \mathrm{M}$ indomethacin, $1 \mu \mathrm{M}$ dexamethasone and $0.5 \mathrm{mM} / \mathrm{ml} 3$-isobutyl-1-methylxanthine in $\alpha$-MEM. We found that the amount of lipid droplets was significantly increased in the miR342-3p mimic-transfected cells compared with the control-transfected cells on day 12 after 


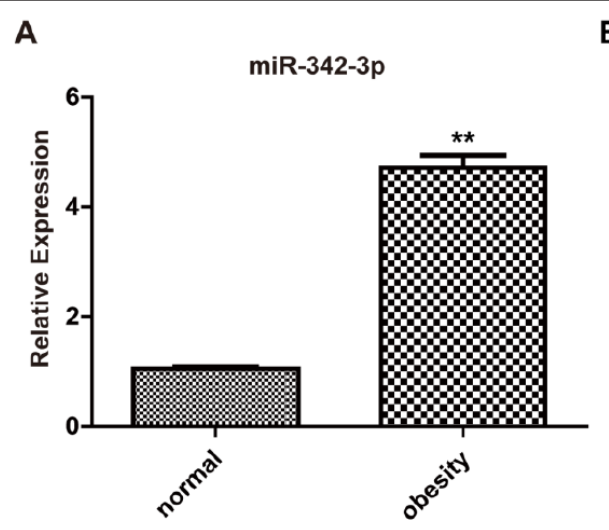

B

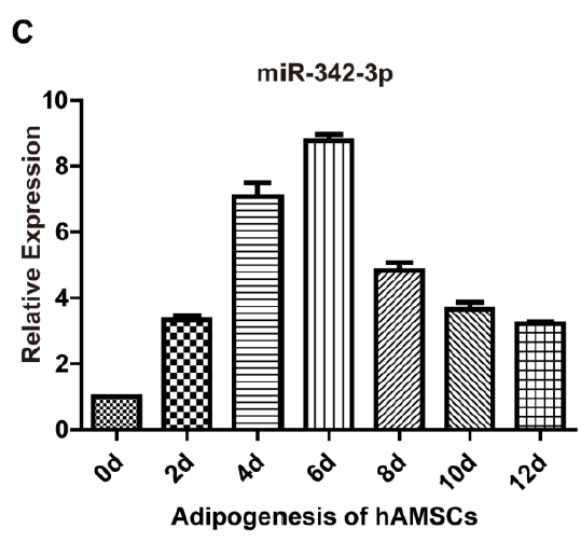

D
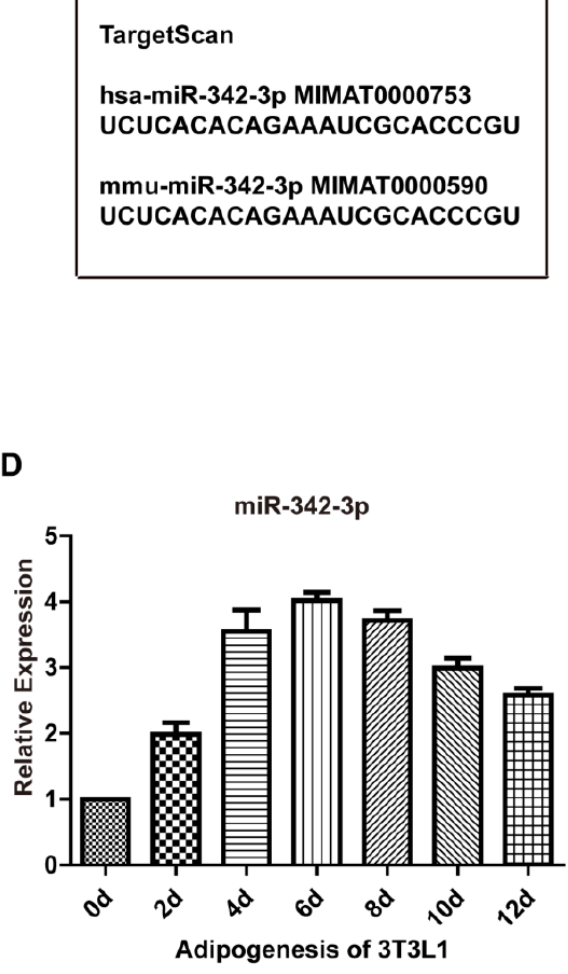

Fig. 1. MiR-342-3p expression profile. qRT-PCRwas performed to determinethe expression of miR-342-3p in obesemice compared with normal mice $(n=5)$. (B) The conservation of miR-342-3p between humansand mice. (C and D)Thedynamic expression pattern of miR-342-3p during the adipogenic differentiation of hAMSCs and 3T3L1, respectively, as detected by qRT-PCR.

induction, as determined by Oil Red 0 staining (Fig. 2B). The overexpression of miR-342-3p enhanced absorbance by approximately 1.88 -fold, as determined by measuring the OD of Oil Red 0 extractions at $510 \mathrm{~nm}$ (Fig. 2C), and resulted in a significant increase in the triglyceride concentration compared with the negative control-transfected cells, as determined by triglyceride concentration assays (Fig. 2D).

The induction of adipocyte-specific transcription factors and markers was also detected by qRT-PCR. The mRNA levels of PPAR $\gamma, \mathrm{C} / \mathrm{EBP} \alpha, \mathrm{FABP} 4$ and LPL were all significantly increased following the transfection of miR-342-3p mimics into hAMSCs during adipogenic differentiation (Fig. 2E). Consistent with these results, western blot analysis showed that the protein levels of PPAR $\gamma, \mathrm{C} / \mathrm{EBP} \alpha, \mathrm{FABP} 4$ and LPL were elevated following adipogenic treatment in the cells transfected with miR-342-3p mimics (Fig. 2F).

Inhibition of miR-342-3p blocks adipogenic differentiation of hAMSCs

To further investigate the effects of miR-342-3p on hAMSC differentiation, we transfected hAMSCs with a specific miRNA inhibitor (miR-342-3p inhibitor, 342-3pI). qRT-PCR analysis showed that the transfection of miR-342-3p inhibitor effectively downregulated miR-342$3 p$ expression in the hAMSCs (Fig. 3A). To clarify the effect of miR-342-3p inhibition on adipogenic differentiation, miR-342-3pI-transfected AMSCs were induced to differentiate into adipogenic lineages. Oil Red 0 staining revealed that the inhibition of miR-342-3p suppressed lipid droplet accumulation in the process of adipogenic differentiation of the hAMSCs (Fig. 3B), which was quantified by measuring the OD of Oil Red 0 extractions at 


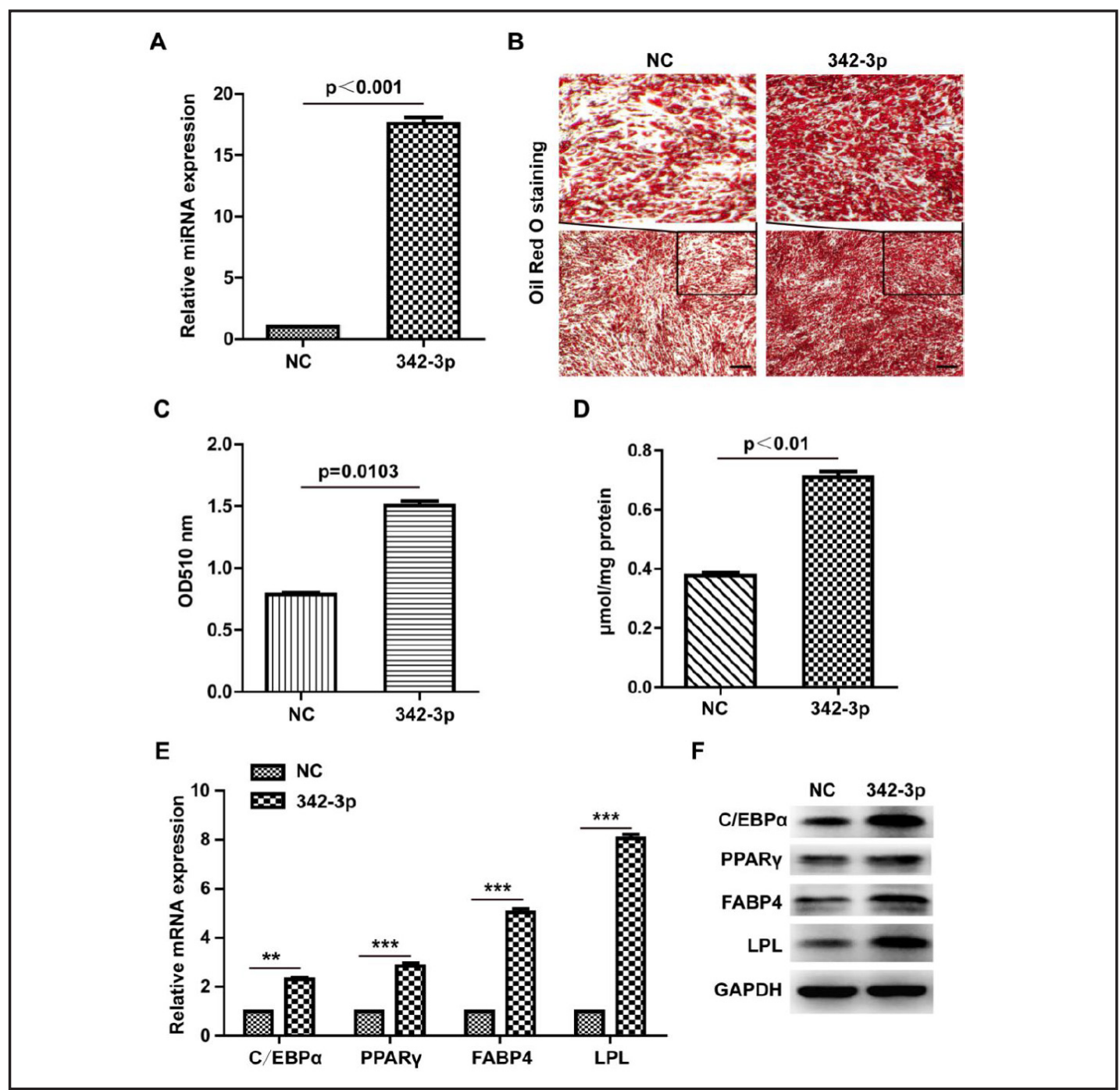

Fig. 2. MiR-342-3p overexpression promotes adipogenic differentiation. miR-342-3p levels were determined in negative control (NC)- or miR-342-3p (342-3p)-transfected hAMSCs using qRT-PCR. The data are presented as the relative ratio of the level of miR-342-3p to that of U6 for each sample. (B and C) Lipid accumulation was determined by Oil Red 0 staining and quantified by measuring absorbance at $510 \mathrm{~nm}$. (D) The triglyceride concentrations in induced cells on day 12 of differentiation. (E and F) The mRNA and protein levels of adipogenic regulators and marker genes in induced cells were analyzed on day 9 of differentiation by qRT-PCR and western blot, respectively. The qPCR data are presentedas the mean \pm SEM $(n=3) . * *<0.01$, and $* * * P<0.001$.

$510 \mathrm{~nm}$ (Fig. 3C). Consistent with these results, triglyceride concentration assays indicated a decrease in the triglyceride concentration compared with the inhibitor negative control (NCI)-transfected cells (Fig. 3D). To further confirm this finding, we analyzed the expression of adipocyte-specific transcription factors and marker genes by qRT-PCR and western blot. The results showed that the inhibition of miR-342-3p decreased the expression of PPAR $\gamma, \mathrm{C} /$ EBP $\alpha$, FABP4 and LPL during the adipogenic differentiation of the hAMSCs (Fig. 3E and F). These results demonstrated that adipocyte formation was significantly blocked by miR-342$3 p$ downregulation.

MiR-342-3p targets the 3 'UTR of CtBP2 mRNA

To investigate the molecular mechanism underlying the regulation of the adipogenic differentiation of hAMSCs by miR-342-3p, several miRNA target prediction tools were used 


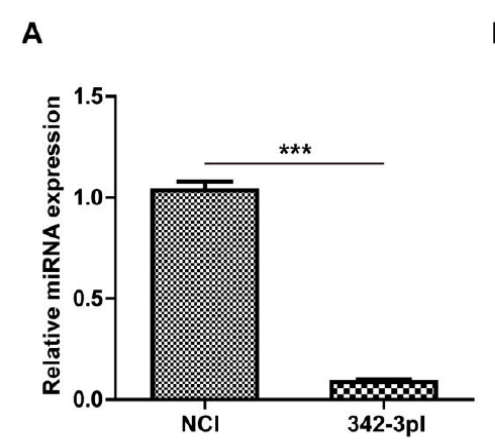

C

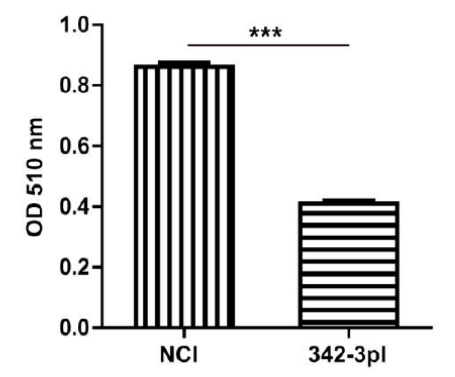

E

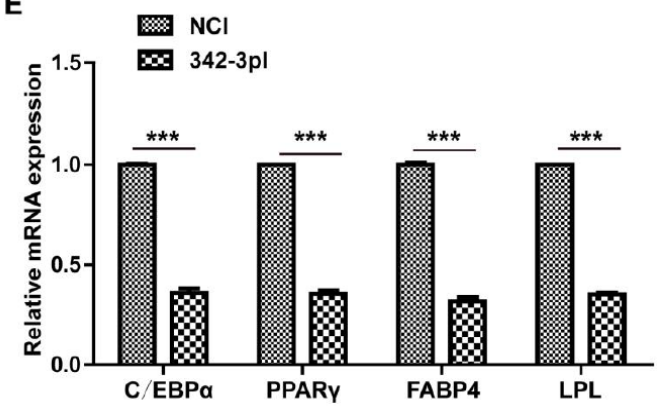

B

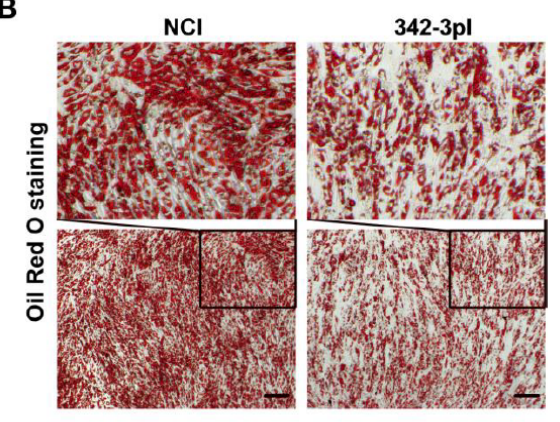

D

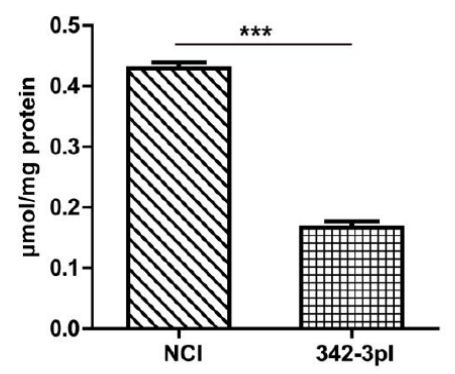

$\mathbf{F}$

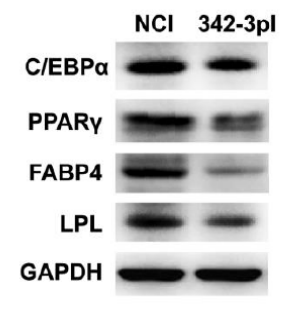

Fig. 3. Inhibition of miR-342-3p blocks adipogenic differentiation. miR-342-3p levels were determined in miR-342-3p inhibitor (342-3pI)- or inhibitor negative control (NCI)-transfected hAMSCs using qRT-PCR. The data are presented as the relative ratio of the level of miR-342-3p to that of U6 for each sample. (B and C) Lipid accumulation was determined by Oil Red 0 staining and quantified by measuring absorbance at 510 $\mathrm{nm}$ in the miR-342-3pI- and miR-NCI-transfected hAMSCs during adipogenic differentiation on day 12. (D) The triglyceride concentrations in induced hAMSCs transfected with miR-342-3pI or miR-NCI on day 12 of differentiation. ( $\mathrm{E}$ and $\mathrm{F}$ ) The mRNA and protein levels of adipogenic regulators and markers in induced cells were analyzed on day 9 of adipogenic differentiation by qRT-PCR and western blot, respectively. ${ }^{* * *} \mathrm{P}<0.001$.

to predict potential targets of this miR. TargetScan suggested a very high likelihood of the targeting of CtBP2 mRNA 3'UTR sequences by mature miR-342-3p (Fig. 4A). CtBP2 mRNA sequences were found to be highly conserved among mammals (Fig. 4B).

To clarify whether miR-342-3p directly targets CtBP2, we constructed luciferase reporter genes with the CtBP2 3'UTR with or without a mutation in the miR-342-3p binding region. The 3'UTR constructs were then cotransfected into 293T cells along with miR-342$3 p$ mimics or NC. Luciferase assay revealed a decrease in relative luciferase activity when the CtBP2 3'UTR (pMIR-CtBP2-W) was transfected into miR-342-3p-transfected 293T cells, while no decrease in activity was observed in 293T cells transfected with the mutant CtBP2 3 'UTR (pMIR-CtBP2-M) (Fig. 4C). In contrast, the miR-342-3p mimics significantly decreased the luciferase activity of the CtBP2 3'UTR construct by $54.9 \%$, whereas transfection with NC had no impact on the mutant 3'UTR construct of CtBP2 (Fig. 4C). To further determine the relationship between miR-342-3p and CtBP2, we detected CtBP2 expression by qRT-PCR and 
A

\begin{tabular}{|l|l|}
\hline & $\begin{array}{l}\text { pridicted consequential pairing of target region (top) } \\
\text { and miRNA (bottom) }\end{array}$ \\
\hline Position 1097-1103 of CTBP2 3' UTR & 5'...GUAUGUUUUGUUUUAGUGUGAGU... \\
hsa-miR-342-3p wt & 3'... UGCCCACGCUAAAGA CACACUCU... \\
hsa-miR-342-3p mut & 3'... UGCCCACGCUAAAGA CUUAGGCU \\
\hline
\end{tabular}

B

$\begin{array}{lll}\text { Hsa } & \text { AGA---AAA---UUUGUUUUAGUGUGAGUUACC-GUUACUGUAU } \\ \text { Ptr } & \text { AGA---AAA---UUUGUUUUAGUGUGAGUUACC-GUUACUGUAU } \\ \text { Mml } & \text { AGA---AAA---UUUGUUUUAGUGUGAGUUACC-GUUACUGUAU } \\ \text { Oga } & \text { AGA---AAA---UUUGUUUUAGUGUGAGUUACC-GUUACUGUAU } \\ \text { The } & \text { AGA---AAA---UUUGUUUUAGUGUGAGUUACC-GUUACUGUAU } \\ \text { Mmu } & \text { AGA---AAA---UUUGUUUUAGUGUGAGUUACC-GUUACUGUAU } \\ \text { Rno } & \text { AGA---AAA---UUUGUUUUAGUGUGAGUUACC-GUUACUGUAU } \\ \text { Cpo } & \text { AGA---AAA---UUUGUUUUAGUGUGAGUUACC-GUUACUGUAU }\end{array}$

C

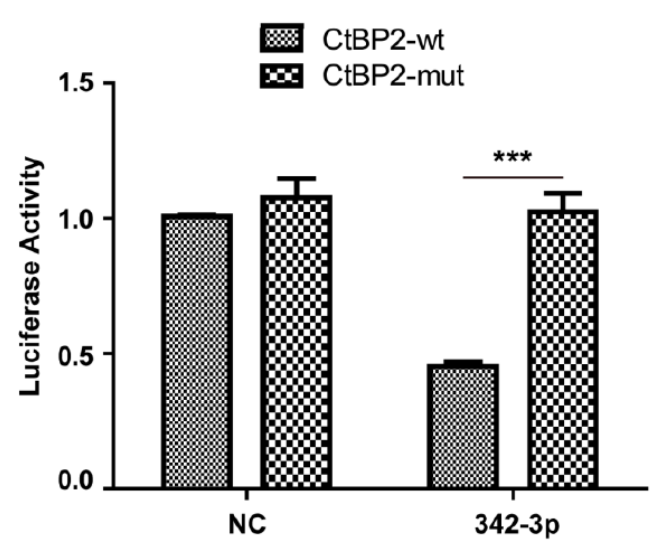

D

E
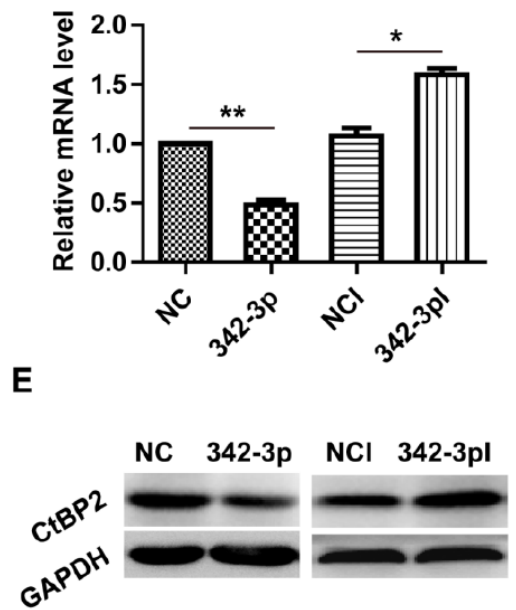

Fig. 4. MiR-342-3p directly targets the 3 'UTR of CtBP2 mRNA. (A and B) One potential binding site for miR-342-3p in human CtBP2 3'UTR was predicted by TargetScan, and this binding site of miR-342-3p (in bold characters) is evolutionally conserved. Four nucleotides in the seed region were mutated to abolish the interaction between miR-342-3p and mRNA 3'UTR of CtBP2. (C) The relative luciferase activity was measured using the Dual-Luciferase Reporter Assay System. The transfections were performed in triplicate, and experiments were repeated three times. The luciferase activity was normalized to its $\beta$-galactosidase activity. (D and E) The mRNA and protein levels of CtBP2 were analyzed by qRT-PCR and western blot respectively. GAPDH was used as a loading control. The qRT-PCR data are presented as mean \pm SEM $(n=3)$. ${ }^{*} \mathrm{P}<0.05 .{ }^{* *} \mathrm{P}<0.01 .{ }^{* * *} \mathrm{P}<0.001$.

western blotting during adipocyte differentiation and found that miR-342-3p overexpression led to a marked decrease in CtBP2 expression at both the mRNA and protein levels (Fig. 4D and E).

Inhibition of CtBP2 mimics effects of miR-342-5p on adipogenesis by releasing $C / E B P \alpha$ from CtBP2 binding

To investigate the influence of CtBP2 on the adipogenic differentiation and proliferation of hAMSCs, we suppressed CtBP2 expression in hAMSCs with two siRNAs against CtBP2 


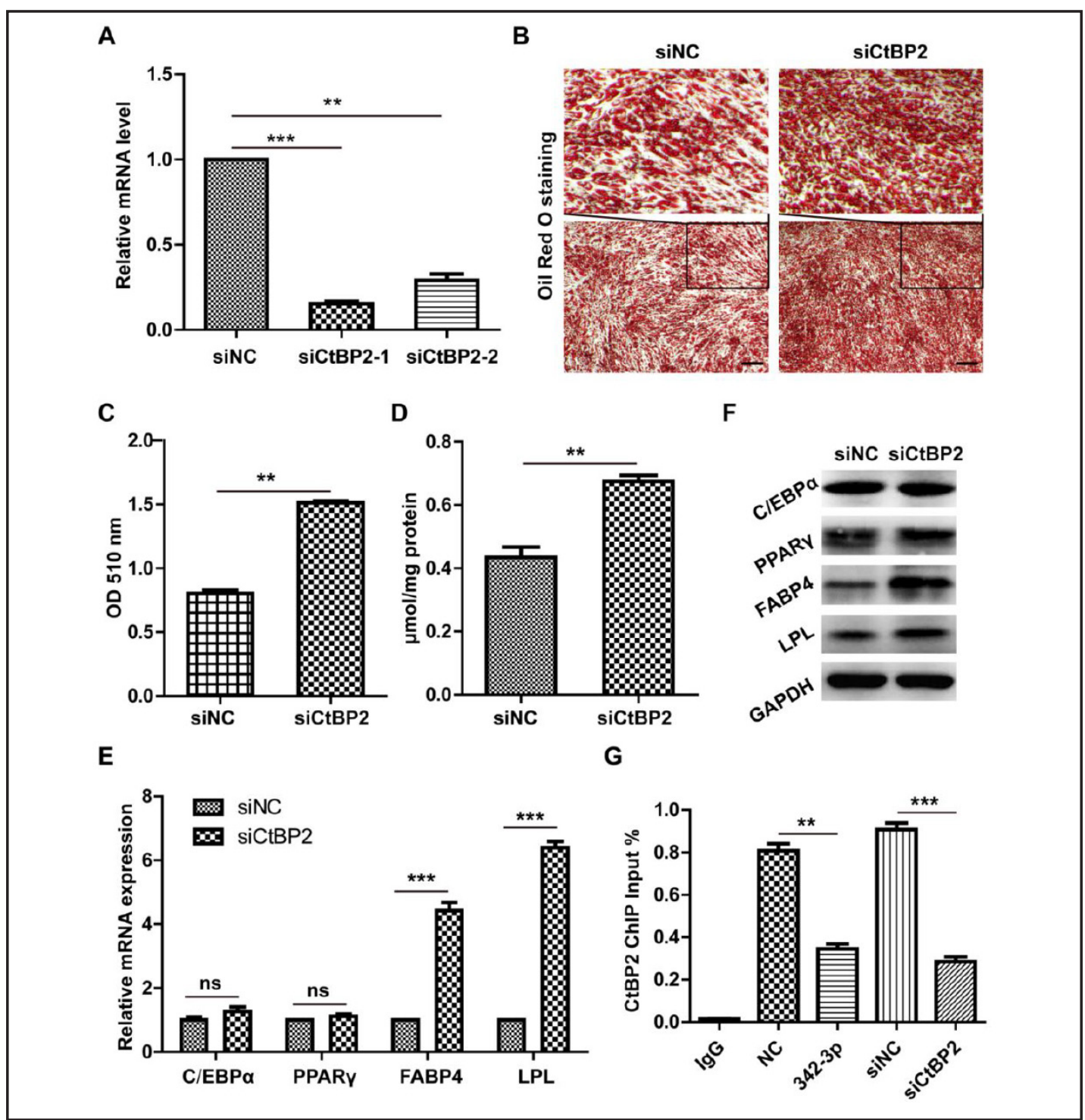

Fig. 5. Inhibition of CtBP2 promotes adipogenic differentiation by releasing C/EBP $\alpha$ and activating adipogenic genes. (A) CtBP2 levels were determined in siCtBP2-1- and siCtBP2-2-transfected or negative control (siNC)-transfected hAMSCs using qRT-PCR. The data are presented as the relative ratio of the level of CtBP2 to that of GAPDH for each sample. (B and C) Lipid accumulation was determined by Oil Red 0 staining and quantified by measuring the absorbance at $510 \mathrm{~nm}$ for the siCtBP2-1- and siNC-transfected hAMSCs during adipogenic differentiation on day 12. (D) The triglyceride concentrations in induced hAMSCs transfected with siCtBP2-1 or siNC on day 12 of adipogenesis. (E and F) The mRNA and protein levels of adipogenic regulators and marker genes in induced cells were analyzed on day 9 of adipogenic differentiation by qRT-PCR and western blotting, respectively. (G) ChIP analysis was performed to confirm the interaction of CtBP2 with $\mathrm{C} / \mathrm{EBP} \alpha$. The qPCR data are presentedas the mean \pm SEM $(\mathrm{n}=3) .{ }^{* *} \mathrm{P}<0.01$, and ${ }^{* * *} \mathrm{P}<0.001$.

(siCtBP2-1 and siCtBP2-2) using an RNA interference technique. First, qRT-PCR analysis was performed, confirming that both siCtBP2-1 and siCtBP2-2 effectively inhibited CtBP2 expression in the hAMSCs (Fig. 5A). Then, siCtBP2-transfected hAMSCs were induced to differentiate into an adipogenic lineage. Oil Red $O$ staining and triglyceride concentration assays showed that the downregulation of CtBP2 resulted in an increase in the accumulation of lipid droplets (Fig. 5B and C). Triglyceride concentration assays also indicated a 55.3\% increase in the triglyceride concentration in the siCtBP2-transfected cells compared with the 
siRNA negative control (siNC)-transfected cells (Fig. 5D). qRT-PCR and western blot analysis also indicated that the downregulation of CtBP2 led to significant increases in the mRNA and protein levels of the adipogenic marker genes FABP4 and LPL but not those of PPAR $\gamma$ or C/ EBP $\alpha$ (Fig. 5E and F), implying that CtBP2 acts downstream of C/EBP $\alpha$ as a transcriptional corepressor [47]. To investigate this possibility, we immunoprecipitated C/EBP $\alpha$ complexes in hAMSC adipocytes treated with miR-342-3p mimics or their respective negative control (NC) and analyzed the associated proteins by PCR. Consistent with siCtBP2, the results showed that miR-342-3p can significantly decrease the interaction of CtBP2 with C/EBP $\alpha$ during adipogenic differentiation and subsequently activate the expression of adipogenic genes, such as FABP4 and LPL (Fig. 5G).

\section{Discussion}

MiR-342-3p as a relatively new member of the miRNA family, and there are few studies that have evaluated it. miR-342-3p had been found to be upregulated in experimental and idiopathic prion disease, suggesting that it may be used as a novel marker for animal and human bovine spongiform encephalopathy [49]. A high level of miR-342-3p has been associated with significantly worse survival in patients with colon cancer [50]. More recently, it has been reported that miR-342-3p suppresses proliferation, migration and invasion by targeting FOXM1 in human cervical cancer [51]. This miR has also been found to be significantly elevated in irritable bowel syndrome patients [52]. However, there has been no report of the involvement of miR-342-3p in regulating cell differentiation to date. Previous studies have found that it is activated and upregulated in the adipose tissue of mice fed a high-fat diet $[53,54]$. However, its functional roles were not been investigated in these earlier reports. In this study, we revealed that the level of miR-342-3p was significantly elevated during the adipogenic differentiation of hAMSCs and 3T3L1 cells. Using gainand loss-of-function assays, we demonstrated that miR-342-3p significantly promoted the differentiation of hMSCs into an adipogenic lineage. We also identified and validated that CtBP2 was a direct target of miR-342-3p in this process.

Adipogenesis, which plays roles in diseases including obesity, insulin resistance and type 2 diabetes $[55,56]$, is a dynamic and complex process that involves clonal expansion, cell cycle exit and terminal differentiation into mature adipocytes $[57,58]$. It is regulated by multiple adipogenic transcription factors, and CCAAT/enhancer-binding protein (C/EBP $\alpha$ ) and peroxisome proliferator-activated receptor $\gamma$ (PPAR $\gamma$ ) are two master regulators of preadipocyte differentiation $[4,59,60]$. During the process of adipocyte differentiation, lipid droplets are gradually produced, and cells are filled with fatty droplets until a final large fat droplet is formed [61]. Here, we found that the overexpression of miR-342-3p promoted the expression of adipogenic marker genes (C/EBP $\alpha, \operatorname{PPAR} \gamma, \mathrm{FABP} 4$ and LPL) as well as lipid droplet accumulation and increased triglyceride concentrations, indicating its important role in the adipogenesis of hAMSCs. We applied several target prediction tools to predict potential targets for miR-342-3p. Then, luciferase reporter gene assay was performed, and the results indicated that miR-342-3p directly targeted the 3'UTR of C-terminal-binding protein 2 (CtBP2) and that both the mRNA and protein levels of this protein were regulated by miR-342-3p. These results suggest that the suppression of CtBP2 by miR-342-3p may occur via either promoting its degradation or inhibiting its translation.

CtBP family proteins are conserved among vertebrates and invertebrates and function as transcriptional corepressors [62-64]. Previous studies have found that CtBP1 and CtBP2 repress gene transcription and play important roles in development and oncogenesis [65]. Enriched CtBP2 expression has been reported in stem cells, and this protein has been demonstrated to have an important role in stem cell maintenance and the regulation of differentiation in ESCs [66]. CtBP2 has also been identified as a coactivator that is critical for retinoic acid (RA)-induced transcription in mouse F9 cells [67]. CtBP1 and CtBP2 have been reported to directly interact with PRDM16 and selectively mediate the repression 


\section{Cellular Physiology Cell Physiol Biochem 2015;35:2285-2298 \begin{tabular}{|l|l|} 
DOI: 10.1159/000374032 & O 2015 S. Karger AG, Basel
\end{tabular} and Biochemistry Published online: April 13, 2015 www.karger.com/cpb \\ Wang et al.: MiR-342-3p Regulates Adipogenesis via Suppressing CtBP2}

of white fat genes by recruiting a PRDM16/CtBP complex to their promoters [68]. The repression of adipogenic maker expression involves the recruitment of CtBP1/2, as directed by $\mathrm{C} / \mathrm{EBP} \alpha$, to the minimal promoters of corresponding genes in response to the PPAR $\gamma$ ligand [47]. However, the role of CtBP2 in the adipocyte differentiation of hMSCs has not been explored to date.

Using two specific siRNAs for CtBP2, we downregulated CtBP2 expression in hMSCs during adipocyte differentiation and found that its inhibition resulted in the enhanced accumulation of lipid droplets, increased triglyceride concentrations, and increases in the expression levels of the adipogenic marker genes FABP4 and LPL. However, the expression levels of PPAR $\gamma$ and C/EBP $\alpha$ did not change in response to the downregulation of CtBP2 during adipogenic differentiation, implying that this protein may act downstream of $\mathrm{C} /$ $\mathrm{EBP} \alpha$ as a transcriptional corepressor. Co-immunoprecipitation assay confirmed that the overexpression of miR-342-3p in hAMSCs significantly decreases the interaction of CtBP2 with $\mathrm{C} / \mathrm{EBP} \alpha$ during the process of adipogenesis. CtBP2 downregulation promoted an increase in adipogenesis similar to that caused by the miR-342-3p mimics, and its effects were not influenced by the adipogenic inhibition caused by the miR-342-3p oligonucleotide inhibitor. Furthermore, the inhibition of miR-342-3p was largely counteracted by the inhibition of CtBP2 during adipogenic differentiation. However, the suppression of CtBP2 was not responsible for the moderate activation of PPAR $\gamma$ or C/EBP $\alpha$ by miR-342-3p overexpression, suggesting that there may be other target genes that also play roles in this process.

In conclusion, our study demonstrated that miR-342-3p, which is a powerful enhancer of adipogenesis, directly targeted and inhibited the expression of CtBP2 (a corepressor of the initial factor, $\mathrm{C} / \mathrm{EBP} \alpha$ ) at the posttranscriptional level. Further, we showed that C/EBP $\alpha$ was released from CtBP2 binding and in turn recruited and activated the transcription of adipogenic marker genes. Our findings indicate that miR-342-3p is a potential target for adipose tissue engineering and the management of obesity and other metabolic diseases.

\section{Disclosure Statement}

The authors declare that there are no conflicts of interest.

\section{Acknowledgements}

This research was supported by American Journal Experts language revision services.

\section{References}

1 Trayhurn P: Endocrine and signalling role of adipose tissue: New perspectives on fat. Acta Physiol Scand 2005;184:285-293.

2 Rossner S: Obesity: The disease of the twenty-first century. Int J Obes Relat Metab Disord 2002;26:S2-4.

3 Rahmouni K, Correia ML, Haynes WG, Mark AL: Obesity-associated hypertension: New insights into mechanisms. Hypertension 2005;45:9-14.

4 Lefterova MI, Lazar MA: New developments in adipogenesis. Trends Endocrinol Metab 2009;20:107-114.

5 Braun J, Hack A, Weis-Klemm M, Conrad S, Treml S, Kohler K, Walliser U, Skutella T, Aicher WK: Evaluation of the osteogenic and chondrogenic differentiation capacities of equine adipose tissue-derived mesenchymal stem cells. Am J Vet Res 2010;71:1228-1236.

6 Schaffler A, Buchler C: Concise review: Adipose tissue-derived stromal cells--basic and clinical implications for novel cell-based therapies. Stem Cells 2007;25:818-827. 


\section{Cellular Physiology Cell Physiol Biochem 2015;35:2285-2298 \begin{tabular}{l|l|l} 
DOI: 10.1159/000374032 & C 2015 S. Karger AG, Basel
\end{tabular} and Biochemistry Published online: April 13, 2015

Wang et al.: MiR-342-3p Regulates Adipogenesis via Suppressing CtBP2

7 Cao Y, Sun Z, Liao L, Meng Y, Han Q, Zhao RC: Human adipose tissue-derived stem cells differentiate into endothelial cells in vitro and improve postnatal neovascularization in vivo. Biochem Biophys Res Commun 2005;332:370-379.

8 Zuk PA, Zhu M, Mizuno H, Huang J, Futrell JW, Katz AJ, Benhaim P, Lorenz HP, Hedrick MH: Multilineage cells from human adipose tissue: Implications for cell-based therapies. Tissue Eng 2001;7:211-228.

9 Fabian MR, Sonenberg N: The mechanics of mirna-mediated gene silencing: A look under the hood of mirisc. Nat Struct Mol Biol 2012;19:586-593.

10 Gangaraju VK, Lin H: Micrornas: Key regulators of stem cells. Nat Rev Mol Cell Biol 2009;10:116-125.

11 O'Loghlen A, Munoz-Cabello AM, Gaspar-Maia A, Wu HA, Banito A, Kunowska N, Racek T, Pemberton HN, Beolchi P, Lavial F, Masui O, Vermeulen M, Carroll T, Graumann J, Heard E, Dillon N, Azuara V, Snijders AP, Peters G, Bernstein E, Gil J: Microrna regulation of cbx7 mediates a switch of polycomb orthologs during esc differentiation. Cell Stem Cell 2012;10:33-46.

12 Tan PX, Du SS, Ren C, Yao QW, Zheng R, Li R, Yuan YW: Microrna-207 enhances radiation-induced apoptosis by directly targeting akt3 in cochlea hair cells. Cell Death Dis 2014;5:e1433.

13 Song SJ, Ito K, Ala U, Kats L, Webster K, Sun SM, Jongen-Lavrencic M, Manova-Todorova K, Teruya-Feldstein J, Avigan DE, Delwel R, Pandolfi PP: The oncogenic microrna mir-22 targets the tet2 tumor suppressor to promote hematopoietic stem cell self-renewal and transformation. Cell Stem Cell 2013;13:87-101.

14 Kim YJ, Bae SW, Yu SS, Bae YC, Jung JS: Mir-196a regulates proliferation and osteogenic differentiation in mesenchymal stem cells derived from human adipose tissue. J Bone Miner Res 2009;24:816-825.

15 Zhang J, Tu Q, Bonewald LF, He X, Stein G, Lian J, Chen J: Effects of mir-335-5p in modulating osteogenic differentiation by specifically downregulating wnt antagonist dkk1. J Bone Miner Res 2011;26:1953-1963.

16 Adler JJ, Heller BL, Bringman LR, Ranahan WP, Cocklin RR, Goebl MG, Oh M, Lim HS, Ingham RJ, Wells CD: Amot130 adapts atrophin-1 interacting protein 4 to inhibit yes-associated protein signaling and cell growth. J Biol Chem 2013;288:15181-15193.

17 Trompeter HI, Dreesen J, Hermann E, Iwaniuk KM, Hafner M, Renwick N, Tuschl T, Wernet P: Micrornas mir-26a, mir-26b, and mir-29b accelerate osteogenic differentiation of unrestricted somatic stem cells from human cord blood. BMC Genomics 2013;14:111.

18 Yu S, Geng Q, Ma J, Sun F, Yu Y, Pan Q, Hong A: Heparin-binding egf-like growth factor and mir-1192 exert opposite effect on runx2-induced osteogenic differentiation. Cell Death Dis 2013;4:e868.

19 Zhang WB, Zhong WJ, Wang L: A signal-amplification circuit between mir-218 and wnt/beta-catenin signal promotes human adipose tissue-derived stem cells osteogenic differentiation. Bone 2014;58:59-66.

20 Hupkes M, Sotoca AM, Hendriks JM, van Zoelen EJ, Dechering KJ: Microrna mir-378 promotes bmp2induced osteogenic differentiation of mesenchymal progenitor cells. BMC Mol Biol 2014;15:1.

21 Sun J, Wang Y, Li Y, Zhao G: Downregulation of ppargamma by mir-548d-5p suppresses the adipogenic differentiation of human bone marrow mesenchymal stem cells and enhances their osteogenic potential. J Transl Med 2014;12:168.

22 Kang IH, Jeong BC, Hur SW, Choi H, Choi SH, Ryu JH, Hwang YC, Koh JT: Microrna-302a stimulates osteoblastic differentiation by repressing coup-tfii expression. J Cell Physiol 2015;230:911-921.

23 Luzi E, Marini F, Sala SC, Tognarini I, Galli G, Brandi ML: Osteogenic differentiation of human adipose tissuederived stem cells is modulated by the mir-26a targeting of the smad1 transcription factor. J Bone Miner Res 2008;23:287-295.

24 Li Z, Hassan MQ Volinia S, van Wijnen AJ, Stein JL, Croce CM, Lian JB, Stein GS: A microrna signature for a bmp2-induced osteoblast lineage commitment program. Proc Natl Acad Sci U S A 2008;105:13906-13911.

25 Schaap-Oziemlak AM, Raymakers RA, Bergevoet SM, Gilissen C, Jansen BJ, Adema GJ, Kogler G, le Sage C, Agami R, van der Reijden BA, Jansen JH: Microrna hsa-mir-135b regulates mineralization in osteogenic differentiation of human unrestricted somatic stem cells. Stem Cells Dev 2010;19:877-885.

26 Eskildsen T, Taipaleenmaki H, Stenvang J, Abdallah BM, Ditzel N, Nossent AY, Bak M, Kauppinen S, Kassem M: Microrna-138 regulates osteogenic differentiation of human stromal (mesenchymal) stem cells in vivo. Proc Natl Acad Sci U S A 2011;108:6139-6144.

27 Wu T, Zhou H, Hong Y, Li J, Jiang X, Huang H: Mir-30 family members negatively regulate osteoblast differentiation. J Biol Chem 2012;287:7503-7511.

28 Wu T, Xie M, Wang X, Jiang X, Li J, Huang H: Mir-155 modulates tnf-alpha-inhibited osteogenic differentiation by targeting socs1 expression. Bone 2012;51:498-505. 


\section{Cellular Physiology Cell Physiol Biochem 2015;35:2285-2298 \begin{tabular}{l|l|l}
\hline DOI: 10.1159/000374032 & (C) 2015 S. Karger AG, Basel
\end{tabular} and Biochemistry Published online: April 13, 2015

Wang et al.: MiR-342-3p Regulates Adipogenesis via Suppressing CtBP2

29 Zeng Y, Qu X, Li H, Huang S, Wang S, Xu Q, Lin R, Han Q Li J, Zhao RC: Microrna-100 regulates osteogenic differentiation of human adipose-derived mesenchymal stem cells by targeting bmpr2. FEBS Lett 2012;586:2375-2381.

30 Kim EJ, Kang IH, Lee JW, Jang WG, Koh JT: Mir-433 mediates errgamma-suppressed osteoblast differentiation via direct targeting to runx2 mrna in c3h10t1/2 cells. Life Sci 2013;92:562-568.

31 Jia J, Tian Q Ling S, Liu Y, Yang S, Shao Z: Mir-145 suppresses osteogenic differentiation by targeting sp7. FEBS Lett 2013;587:3027-3031.

32 Li E, Zhang J, Yuan T, Ma B: Mir-143 suppresses osteogenic differentiation by targeting osterix. Mol Cell Biochem 2014;390:69-74.

33 Kureel J, Dixit M, Tyagi AM, Mansoori MN, Srivastava K, Raghuvanshi A, Maurya R, Trivedi R, Goel A, Singh D: Mir-542-3p suppresses osteoblast cell proliferation and differentiation, targets bmp-7 signaling and inhibits bone formation. Cell Death Dis 2014;5:e1050.

34 Liu H, Sun Q, Wan C, Li L, Zhang L, Chen Z: Microrna-338-3p regulates osteogenic differentiation of mouse bone marrow stromal stem cells by targeting runx2 and fgfr2. J Cell Physiol 2014;229:1494-1502.

35 Hwang S, Park SK, Lee HY, Kim SW, Lee JS, Choi EK, You D, Kim CS, Suh N: Mir-140-5p suppresses bmp2mediated osteogenesis in undifferentiated human mesenchymal stem cells. FEBS Lett 2014;588:29572963.

36 Esau C, Kang X, Peralta E, Hanson E, Marcusson EG, Ravichandran LV, Sun Y, Koo S, Perera RJ, Jain R, Dean NM, Freier SM, Bennett CF, Lollo B, Griffey R: Microrna-143 regulates adipocyte differentiation. J Biol Chem 2004;279:52361-52365.

37 Wang Q, Li YC, Wang J, Kong J, Qi Y, Quigg RJ, Li X: Mir-17-92 cluster accelerates adipocyte differentiation by negatively regulating tumor-suppressor rb2/p130. Proc Natl Acad Sci U S A 2008;105:2889-2894.

38 Lee EK, Lee MJ, Abdelmohsen K, Kim W, Kim MM, Srikantan S, Martindale JL, Hutchison ER, Kim HH, Marasa BS, Selimyan R, Egan JM, Smith SR, Fried SK, Gorospe M: Mir-130 suppresses adipogenesis by inhibiting peroxisome proliferator-activated receptor gamma expression. Mol Cell Biol 2011;31:626-638.

39 Li H, Li T, Wang S, Wei J, Fan J, Li J, Han Q, Liao L, Shao C, Zhao RC: Mir-17-5p and mir-106a are involved in the balance between osteogenic and adipogenic differentiation of adipose-derived mesenchymal stem cells. Stem Cell Res 2013;10:313-324.

40 Liang WC, Wang Y, Wan DC, Yeung VS, Waye MM: Characterization of mir-210 in 3t3-l1 adipogenesis. J Cell Biochem 2013;114:2699-2707.

41 Chen H, Mo D, Li M, Zhang Y, Chen L, Zhang X, Zhou X, Chen Y: Mir-709 inhibits 3t3-l1 cell differentiation by targeting gsk3beta of wnt/beta-catenin signaling. Cell Signal 2014;26:2583-2589.

42 Yang Z, Bian C, Zhou H, Huang S, Wang S, Liao L, Zhao RC: Microrna hsa-mir-138 inhibits adipogenic differentiation of human adipose tissue-derived mesenchymal stem cells through adenovirus eid-1. Stem Cells Dev 2011;20:259-267.

43 Shin KK, Kim YS, Kim JY, Bae YC, Jung JS: Mir-137 controls proliferation and differentiation of human adipose tissue stromal cells. Cell Physiol Biochem 2014;33:758-768.

44 Hamam D, Ali D, Vishnubalaji R, Hamam R, Al-Nbaheen M, Chen L, Kassem M, Aldahmash A, Alajez NM: Microrna-320/runx2 axis regulates adipocytic differentiation of human mesenchymal (skeletal) stem cells. Cell Death Dis 2014;5:e1499.

45 Karbiener M, Neuhold C, Opriessnig P, Prokesch A, Bogner-Strauss JG, Scheideler M: Microrna-30c promotes human adipocyte differentiation and co-represses pai-1 and alk2. RNA Biol 2011;8:850-860.

46 Chartoumpekis DV, Zaravinos A, Ziros PG, Iskrenova RP, Psyrogiannis AI, Kyriazopoulou VE, Habeos IG: Differential expression of micrornas in adipose tissue after long-term high-fat diet-induced obesity in mice. PLoS One 2012;7:e34872.

47 Vernochet C, Peres SB, Davis KE, McDonald ME, Qiang L, Wang H, Scherer PE, Farmer SR: C/ebpalpha and the corepressors ctbp1 and ctbp2 regulate repression of select visceral white adipose genes during induction of the brown phenotype in white adipocytes by peroxisome proliferator-activated receptor gamma agonists. Mol Cell Biol 2009;29:4714-4728.

48 Zuk PA, Zhu M, Ashjian P, De Ugarte DA, Huang JI, Mizuno H, Alfonso ZC, Fraser JK, Benhaim P, Hedrick MH: Human adipose tissue is a source of multipotent stem cells. Mol Biol Cell 2002;13:4279-4295.

49 Montag J, Hitt R, Opitz L, Schulz-Schaeffer WJ, Hunsmann G, Motzkus D: Upregulation of mirna hsa-mir342-3p in experimental and idiopathic prion disease. Mol Neurodegener 2009;4:36. 


\section{Cellular Physiology Cell Physiol Biochem 2015;35:2285-2298 \begin{tabular}{l|l|}
\cline { 2 - 2 } DOI: 10.1159/000374032 & 015 S. Karger AG, Basel
\end{tabular} www.karger.com/cpb \\ Wang et al.: MiR-342-3p Regulates Adipogenesis via Suppressing CtBP2}

50 Tao K, Yang J, Guo Z, Hu Y, Sheng H, Gao H, Yu H: Prognostic value of mir-221-3p, mir-342-3p and mir-4915p expression in colon cancer. Am J Transl Res 2014;6:391-401.

51 Li XR, Chu HJ, Lv T, Wang L, Kong SF, Dai SZ: Mir-342-3p suppresses proliferation, migration and invasion by targeting foxm1 in human cervical cancer. FEBS Lett 2014;588:3298-3307.

52 Fourie NH, Peace RM, Abey SK, Sherwin LB, Rahim-Williams B, Smyser PA, Wiley JW, Henderson WA: Elevated circulating mir-150 and mir-342-3p in patients with irritable bowel syndrome. Exp Mol Pathol 2014;96:422-425.

53 Meyre D, Froguel P, Horber FF, Kral JG: Comment on: Valette et al. Melanocortin-4 receptor mutations and polymorphisms do not affect weight loss after bariatric surgery. Plos one 2012;7:E48221. PLoS One 2014;9:e93324.

54 Oger F, Gheeraert C, Mogilenko D, Benomar Y, Molendi-Coste O, Bouchaert E, Caron S, Dombrowicz D, Pattou F, Duez H, Eeckhoute J, Staels B, Lefebvre P: Cell-specific dysregulation of microrna expression in obese white adipose tissue. J Clin Endocrinol Metab 2014;99:2821-2833.

55 Spiegelman BM, Flier JS: Obesity and the regulation of energy balance. Cell 2001;104:531-543.

56 Flier JS: Obesity wars: Molecular progress confronts an expanding epidemic. Cell 2004;116:337-350.

57 Feve B: Adipogenesis: Cellular and molecular aspects. Best Pract Res Clin Endocrinol Metab 2005;19:483499.

58 Gummersbach C, Hemmrich K, Kroncke KD, Suschek CV, Fehsel K, Pallua N: New aspects of adipogenesis: Radicals and oxidative stress. Differentiation 2009;77:115-120.

59 Tontonoz P, Hu E, Graves RA, Budavari AI, Spiegelman BM: Mppar gamma 2: Tissue-specific regulator of an adipocyte enhancer. Genes Dev 1994;8:1224-1234.

60 Lane MD, Tang QQ Jiang MS: Role of the ccaat enhancer binding proteins (c/ebps) in adipocyte differentiation. Biochem Biophys Res Commun 1999;266:677-683.

61 Desruisseaux MS, Nagajyothi, Trujillo ME, Tanowitz HB, Scherer PE: Adipocyte, adipose tissue, and infectious disease. Infect Immun 2007;75:1066-1078.

62 Chinnadurai G: Ctbp, an unconventional transcriptional corepressor in development and oncogenesis. Mol Cell 2002;9:213-224.

63 Zhao LJ, Subramanian T, Vijayalingam S, Chinnadurai G: Ctbp2 proteome: Role of ctbp in e2f 7-mediated repression and cell proliferation. Genes Cancer 2014;5:31-40.

64 Zhang C, Gao C, Xu Y, Zhang Z: Ctbp2 could promote prostate cancer cell proliferation through c-myc signaling. Gene 2014;546:73-79.

65 Paliwal S, Ho N, Parker D, Grossman SR: Ctbp2 promotes human cancer cell migration by transcriptional activation of tiam1. Genes Cancer 2012;3:481-490.

66 Tarleton HP, Lemischka IR: Delayed differentiation in embryonic stem cells and mesodermal progenitors in the absence of ctbp2. Mech Dev 2010;127:107-119.

67 Bajpe PK, Heynen GJ, Mittempergher L, Grernrum W, de Rink IA, Nijkamp W, Beijersbergen RL, Bernards $\mathrm{R}$, Huang S: The corepressor ctbp2 is a coactivator of retinoic acid receptor/retinoid x receptor in retinoic acid signaling. Mol Cell Biol 2013;33:3343-3353.

68 Kajimura S, Seale P, Tomaru T, Erdjument-Bromage H, Cooper MP, Ruas JL, Chin S, Tempst P, Lazar MA, Spiegelman BM: Regulation of the brown and white fat gene programs through a prdm16/ctbp transcriptional complex. Genes Dev 2008;22:1397-1409. 